\title{
Patient-controlled analgesia in the pediatric population: morphine versus hydromorphone
}

This article was published in the following Dove Press journal:

Journal of Pain Research

13 August 2014

Number of times this article has been viewed

\author{
Matthew DiGiusto ${ }^{2}$ \\ Tarun Bhalla' \\ David Martin' \\ Derek Foerschler ${ }^{3}$ \\ Megan J Jones² \\ Joseph D Tobias' \\ 'Department of Anesthesiology \\ and Pain Medicine, Nationwide \\ Children's Hospital and the Ohio \\ State University, ${ }^{2}$ The Ohio State \\ School of Medicine, ${ }^{3}$ Department \\ of Anesthesiology, The Ohio State \\ University, Columbus, $\mathrm{OH}$, USA
}

Correspondence: Tarun Bhalla Department of Anesthesiology and Pain Medicine, Nationwide Children's Hospital, 700 Children's Drive, Columbus, $\mathrm{OH} 43205$, USA

$\mathrm{Tel}+\mathrm{I} 6147224200$

Fax + I 614722 4203

Email tarun.bhalla@nationwidechildrens.org
Objective: Patient controlled analgesia (PCA) is commonly used to provide analgesia following surgical procedures in the pediatric population. Morphine and hydromorphone remain the most commonly used opioids for PCA. Although both are effective, adverse effects may occur. When these adverse effects are unremitting or severe, opioid rotation may be required. In this study, we retrospectively evaluated PCA use, the adverse effect profile, and the frequency of opioid rotation.

Methods: This retrospective study was performed at Nationwide Children's Hospital (Columbus, OH). The hospital's electronic registry was queried for PCA use delivering either morphine or hydromorphone from January 1, 2008 to December 31, 2010.

Results: A total of 514 patients were identified, that met study entry criteria. Of the 514 cases, $298(56.2 \%)$ were initially started on morphine and $225(43.8 \%)$ were initially started on hydromorphone. There were a total of $26(5.1 \%)$ opioid changes in the cohort of 514 patients. Of the 26 switches, 23 of 298 (7.7\%) were from morphine to hydromorphone, and 3 of $225(1.3 \%)$ were from hydromorphone to morphine $(P=0.0008)$. Of the 17 morphine-to-hydromorphone switches with adverse effects, pruritus (64.7\%), and inadequate pain control (47.1\%) were the most common side effects. The most common side effect resulting in a hydromorphone-tomorphine switch was nausea $(66.7 \%)$.

Conclusion: PCA switches from morphine-to-hydromorphone (88.5\%) were more common than vice-versa (11.5\%). The most common reasons for morphine-to-hydromorphone switch were pruritus and inadequate pain control. These data suggest that a prospective study is necessary to determine the side effect differences between morphine and hydromorphone in pediatric PCA.

Keywords: acute pain, analgesia, opioids, pediatric

\section{Introduction}

Morphine and hydromorphone, both $\mu$-opioid receptor agonist analgesics, are associated with typical opioid side effects including nausea, vomiting, pruritus, and cognitive disturbances. ${ }^{1}$ Both opioids are commonly used in patient-controlled analgesia (PCA), a device that delivers preset amounts of intravenous medication to the patient each time a demand button on the PCA pump is depressed. ${ }^{1}$ The use of PCA is currently the mainstay of acute pain management for children over the age of 6 years, given that studies demonstrate improved analgesia, fewer adverse effects, and decreased opioid use when compared to intermittent, on-demand opioid dosing. ${ }^{1-6}$ While both morphine and hydromorphone are $\mu$-opioid receptor agonists, more is known about morphine than any other opioids, and it is commonly referred to as the "gold standard" for pain 
management. ${ }^{1,4,7}$ As the "gold standard", morphine is the first-line medication for postoperative pain control with PCA in the majority of pediatric patients. ${ }^{1}$

There is a belief among health care providers that hydromorphone offers better pain control with fewer side effects compared to morphine, a belief that Hong et $\mathrm{al}^{1}$ refer to as "clinical lore". The reason this belief is referred to as "clinical lore" is because if either drug were consistently found to have fewer side effects with equal or greater efficacy, then it would clearly be the drug of choice; but as it stands, morphine is still considered by most to be the "gold standard". ${ }^{1}$ There are, however, some pharmacological differences between hydromorphone and morphine that may substantiate this "clinical lore". After the administration of either hydromorphone or morphine, the onset of the analgesic effect is rapid, but the time to maximum analgesia is delayed in patients who receive morphine. ${ }^{8}$ This delay in attaining maximum analgesia for morphine is consistent with the hypothesis that one of the metabolites of morphine, morphine-6-glucuronide, plays a role in analgesia. ${ }^{9}$ In the setting of a PCA, a more rapid onset of maximum analgesia could give the patient better pain control. ${ }^{9}$ Additionally, morphine has been shown to induce histamine release while hydromorphone has not. ${ }^{10}$ Histamine release may increase the incidence of one of the undesirable effects of opioids: pruritus. So, while it may be "clinical lore" that hydromorphone has better pain control with fewer side effects when compared to morphine, there is pharmacological evidence that this lore may be a reality.

At the present time, there are limited and inconclusive data that compare the adverse effects of morphine and hydromorphone. Even less information is available on their use in PCA, and virtually no information is available in the pediatric population. We retrospectively surveyed the use of PCA in the pediatric population at our institution and investigated the adverse effect profile of morphine and hydromorphone.

\section{Methods}

Following approval from the Institutional Review Board of the Nationwide Children's Hospital (Columbus, OH, USA), a systemic retrospective review of the medical records was performed to identify patients, ranging in age from 4-13 years who had received a PCA delivering either morphine or hydromorphone from January 1, 2008-December 31, 2010. The exclusion criteria included: 1 ) age $<4$ years or $>13$ years; 2) a chronic pain condition prior to PCA initiation; 3) a history of chronic opioid use; 4) clinically significant comorbid conditions, which may increase the incidence of adverse effects to opioids; and 5) a history of an allergy or previous adverse reaction to any opioid (Figure 1). The patient population we targeted included patients who had limited prior exposure to opioids and those who were being treated for acute pain, as well acute postsurgical pain. This included, but was not limited to, patients attending the orthopedic, pediatric, general surgery, and gastroenterology services.

When a switch was made from one opioid to another, information was extracted as to why the switch was made. Pain was assessed by scores on the Visual Analog Scale (a score $>6$ warrants intervention) or scores on the Wong-Baker Faces Pain Rating Scale (a score $>2$ warrants intervention). ${ }^{9}$ The typical protocol followed by the pain team in patients with narcotic-related side effects is initiating a naloxone infusion at a dose of $0.25-0.75 \mu \mathrm{g} / \mathrm{kg} / \mathrm{hour}$ in conjunction with adjuvant therapy (ondansetron or diphenhydramine). If the initial steps of side-effect management were unsuccessful (as per the discretion of patient, bedside nurse, and pain team), the narcotic PCA was switched. The incidence of switching from morphine to hydromorphone versus hydromorphone to morphine, as well as the incidence of adverse effects, were compared using

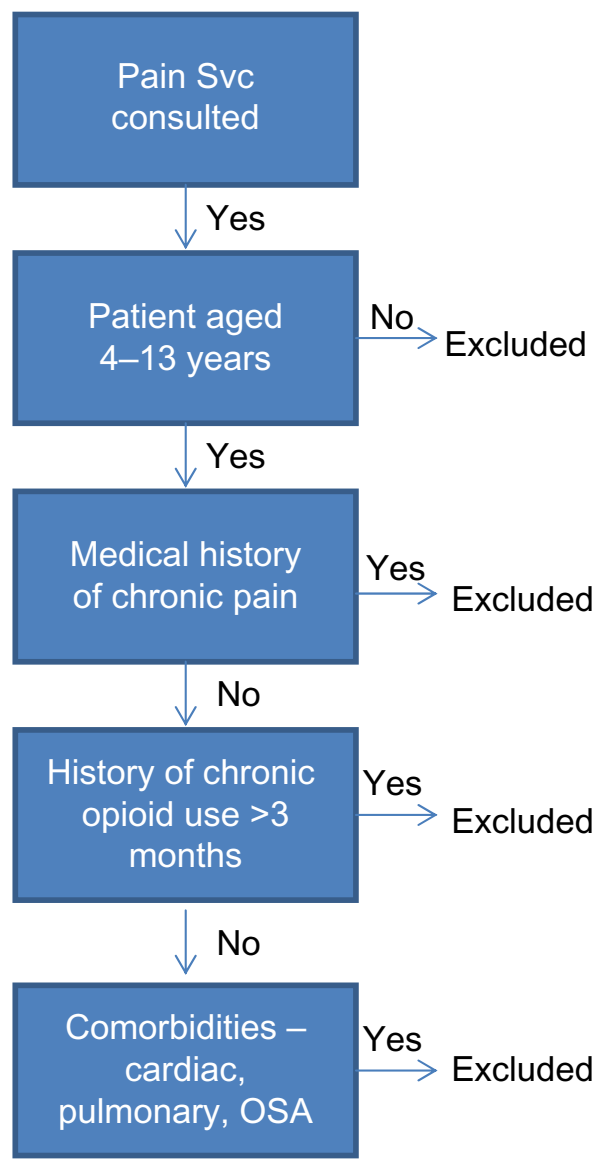

Figure I Inclusion/exclusion flowchart. Abbreviations: Svc, service; OSA, obstructive sleep apnea. 
a contingency table and Fisher's exact test. Demographic data including patients' age and weight were compared using a unpaired $t$-test. The data are presented as the mean \pm standard deviation with $P<0.05$ considered significant. The data were collected from the electronic medical records (EpicCare EMR; Verona, WI, USA) and maintained in an internal database used by the acute pain service. The initial drug choice was made at the discretion of the prescribing physician, who was usually a member of the anesthesia acute pain team. Unfortunately, this may have led to a selection bias if the physician had a preference in terms of the initial narcotic.

\section{Results}

The cohort for the study included 514 patients. The demographic data of the two groups are presented in Table 1. Of the 514 cases, 298 (56.2\%) were initially started on morphine and $225(43.8 \%)$ were initially started on hydromorphone. In the cohort of 514 patients, 26 required a switch to another opioid, for an incidence of $5.1 \%$. Of the 26 switches, 23 $(88.5 \%)$ were from morphine to hydromorphone and three (11.5\%) were from hydromorphone to morphine (Table 2). Of the 298 patients started on morphine, 23 (7.7\%) were switched to hydromorphone, while only three of $225(1.3 \%)$ were switched from hydromorphone to morphine $(P=0.0008)$. The mean number of days on morphine PCA before switching to hydromorphone was $2.9 \pm 3.1$. The average number of days on hydromorphone PCA before switching to morphine was $2.0 \pm 1.0$ ( $P=$ not significant $)$.

Adverse effects were reported as the reason for the majority of PCA switches (Table 2). Adverse effects were not available for six of the 23 morphine-to-hydromorphone switches. Of the 17 morphine-to-hydromorphone switches with adverse effect data available, pruritus (64.7\%) and inadequate pain control $(47.1 \%)$ were the most common side effects that instigated a change in the PCA opioid (Table 3). The most common adverse effect resulting in a hydromorphone-tomorphine switch was nausea $(66.7 \%)$.

\section{Discussion}

To date, there are limited data available evaluating outcome differences in pediatric patients receiving morphine and hydromorphone delivered via PCA. In 1994, Dunbar et $\mathrm{al}^{3}$ described the efficacy and relative safety of PCA use in children who developed mucositis following bone marrow transplant. The following year, Collins et $\mathrm{al}^{2}$ produced a well-designed crossover study comparing morphine and hydromorphone PCA in children undergoing bone marrow transplant as well. Unfortunately, this was a very small study with a cohort of only ten patients, and no difference in pain control or the adverse effect profile of the two opioids was noted. ${ }^{2}$ In a prospective study comparing morphine with hydromorphone administered via PCA in adults undergoing lower abdominal surgery, a similar analgesic and adverse effect profile was noted. ${ }^{8}$ However, the study included only adults, more than $90 \%$ of whom were females. Hong et $\mathrm{al}^{1}$ performed a similar study in adults, comparing adverse effects between morphine and hydromorphone PCA. The study cohort included 50 adult patients undergoing abdominal or pelvic surgery, and the authors conducted an analysis of the development of nausea, vomiting, or pruritus within the first 8 hours of PCA administration. The authors noted similar pain control with no statistically significant difference in the development of adverse effects in the 8 hours following the initiation of PCA.

A recent meta-analysis by Felden et $\mathrm{al}^{11}$ evaluated the clinical effects of morphine and hydromorphone. The metaanalysis showed a small advantage for hydromorphone for analgesia, but not in regard to the adverse effect profile. The authors noted that the results drawn from two studies in chronic pain patients suggested that there was an advantage of hydromorphone over morphine regarding nausea and vomiting; however, when pooled with all the additional data for acute pain, the effect was not found to be statistically significant. The authors also noted that there are a limited number of studies from which to draw information, and despite the clinical use of hydromorphone for more

Table I Demographic data of the two patient groups*

\begin{tabular}{|c|c|c|c|c|}
\hline & Morphine & Hydromorphone & $\begin{array}{l}\text { Morphine to } \\
\text { hydromorphone }\end{array}$ & $\begin{array}{l}\text { Hydromorphone } \\
\text { to morphine }\end{array}$ \\
\hline Number & 266 & 222 & 23 & 3 \\
\hline Age (years) & $10 \pm 2$ & $11 \pm 3$ & $\mathrm{II} \pm 2$ & $10 \pm 3$ \\
\hline Weight (kg) & $40.0 \pm 17.4$ & $45.6 \pm 20.5$ & $40.3 \pm 14.0$ & $52.0 \pm 30.7$ \\
\hline \multicolumn{5}{|l|}{ Sex } \\
\hline Male & | 44 (54. I\%) & 94 (42.3\%) & I | (47.8\%) & 2 (67.7\%) \\
\hline Female & I 22 (45.9\%) & 128 (57.7\%) & 12 (52.2\%) & I (33.3\%) \\
\hline
\end{tabular}

Note: *There were no statistically significant differences among the groups. 
Table 2 PCA information for the two groups

\begin{tabular}{lll}
\hline & Morphine & Hydromorphone \\
\hline Number & 289 & 225 \\
Only opioid used & $266(92.0 \%)$ & $222(98.7 \%)$ \\
Switched to another opioid & $23(8.0 \%)$ & $3(1.3 \%), P=0.0008$ \\
Number of days on PCA & $2.9 \pm 3.1$ & $2.0 \pm 1.0$ \\
before switching & & \\
\hline
\end{tabular}

Abbreviation: PCA, patient-controlled analgesia.

than 80 years, they suggested that additional randomized controlled trials are required. ${ }^{11}$ A lack of randomized controlled trials is also purported to be the reason for the inability to determine the advantage of hydromorphone over morphine in opioid rotation. ${ }^{12}$ Opioid rotation is a common practice for the improvement of pain control and/or drug tolerability. ${ }^{12}$

Many techniques can be used to combat issues that arise during PCA use. Inadequate pain control may be handled with an increased PCA dosage, the initiation of a basal infusion, or the addition of a secondary analgesic. ${ }^{13}$ Ondansetron may help with nausea and emesis, antihistamines or ondansetron may help with pruritus, and a small-dose naloxone infusion $(0.25-1 \mu \mathrm{g} / \mathrm{kg} /$ hour) can be used to decrease the incidence of nausea, emesis, and pruritis. ${ }^{5}$ When these appropriate interventions have been exhausted and/or when side effects are rapid and severe, rotation to an alternative opioid may help. Among the patients reviewed in our retrospective study, patients who were started on morphine PCA had a higher propensity to be switched than patients started on hydromorphone PCA ( $8 \%$ versus $1.3 \%$, respectively). Pruritus and inadequate pain control were the most common side effects that were cited as being the reason for the change in opioid from morphine to hydromorphone. As previously discussed, there is pharmacological evidence as to why there may be a higher incidence of pruritus and inadequate pain control with morphine as compared to hydromorphone. ${ }^{14-16}$ Given the limited data available in the pediatric literature,

Table 3 Adverse effect profile of two groups*

\begin{tabular}{llll}
\hline & Morphine & Hydromorphone & P-value \\
\hline $\begin{array}{l}\text { Number requiring a } \\
\text { switch to another opioid }\end{array}$ & 23 & 3 & $<0.0008$ \\
$\begin{array}{l}\text { Adverse effects } \\
\text { unavailable }\end{array}$ & 6 & 0 & Not \\
$\begin{array}{l}\text { Pruritus } \\
\text { Inadequate pain control }\end{array}$ & $\mathbf{1 I}(64.7 \%)$ & $\mathrm{I}(33.3 \%)$ & 0.0152 \\
Nausea & $2(11.8 \%)$ & $2(66.7 \%)$ & 0.0105 \\
Cognitive disturbances & $2(11.8 \%)$ & 0 & $\mathrm{NS}$ \\
\end{tabular}

Notes: *Percentages in Table 3 were calculated after subtracting cases where adverse effects were not available. Additionally, some patients developed more than one adverse effect.

Abbreviation: NS, not significant. although retrospective, our study is the largest to date, presenting data on more patients receiving either morphine or hydromorphone administered via PCA. These data suggest that a prospective study should be instituted to more precisely determine the differences in regards to analgesia and the adverse effect profile observed between these two commonly used opioids.

\section{Author contributions}

All authors contributed toward data analysis, drafting and revising the paper and agree to be accountable for all aspects of the work. Matthew DiGiusto: Mr DiGiusto drafted the initial and multiple revisions of the manuscript, as well as tables, and he approved the final manuscript as submitted. Tarun Bhalla: Dr Bhalla helped to conceptualize the study, coordinated and supervised the study design and data collection, critically reviewed the manuscript, and approved the final manuscript as submitted. David Martin: Dr Martin reviewed and revised the manuscript and approved the final manuscript as submitted. Derek Foerschler: Dr Foerschler conceptualized the study, coordinated and collected data for the manuscript, and approved the final manuscript as submitted. Megan J Jones: Ms Jones collected data for the manuscript, revised and critically reviewed the manuscript, and approved the final manuscript as submitted. Joseph D Tobias: Dr Tobias helped to conceptualize the study, supervised data collection, critically reviewed the manuscript, and approved the final manuscript as submitted.

\section{Disclosure}

The authors report no conflicts of interest in this work.

\section{References}

1. Hong D, Flood P, Diaz G. The side effects of morphine and hydromorphone patient-controlled analgesia. Anesth Analg. 2008;107(4): 1384-1389.

2. Collins JJ, Geake J, Grier HE, et al. Patient-controlled analgesia for mucositis pain in children: a three-period crossover study comparing morphine and hydromorphone. J Pediatr. 1996;129(5):722-728.

3. Dunbar PJ, Buckley P, Gavrin JR, Sander JE, Chapman CR. Use of patient-controlled analgesia for pain control for children receiving bone marrow transplant. J Pain Symptom Manage. 1995;10(8):604-611.

4. Lundeberg S, Lönnqvist PA. Update on systemic postoperative analgesia in children. Paediatr Anaesth. 2004;14(5):394-397.

5. Maxwell LG, Kaufmann SC, Blitzer S, et al. The effects of a small-dose naloxone infusion on opioid-induced side effects and analgesia in children and adolescents treated with intravenous patient-controlled analgesia: a double-blind, prospective, randomized, controlled study. Anesth Analg. 2005;100(4):953-958.

6. Monitto CL, Greenberg RS, Kost-Byerly S, et al. The safety and efficacy of parent-/nurse-controlled analgesia in patients less than six year of age. Anesth Analg. 2000;91(3):573-579.

7. Brislin RP, Rose JB. Pediatric acute pain management. Anesthesiol Clin North America. 2005;23(4):789-814, x. 
8. Rapp SE, Egan KJ, Ross BK, Wild LM, Terman GW, Ching JM. A multidimensional comparison of morphine and hydromorphone patient-controlled analgesia. Anesth Analg. 1996;82(5): 1043-1048.

9. Kroemer HK, Klotz U. Glucuronidation of drugs. A re-evaluation of the pharmacological significance of the conjugates and modulating factors. Clin Pharmocokinet. 1992;23(4):292-310.

10. Pick CG, Cheng J, Paul D, Pasternak GW. Genetic influences in opioid analgesic sensitivity in mice. Brain Res. 1991;566(1-2):295-298.

11. Felden L, Walter C, Harder S, et al. Comparative clinical effects of hydromorphone and morphine: a meta-analysis. $\mathrm{Br} J$ Anaesth. 2011;107(3): 319-328.
12. Quigley C. Opioid switching to improve pain relief and drug tolerability. Cochrane Database Syst Rev. 2004;(3):CD004847.

13. Quigley C, Wiffen P. A systemic review of hydromorphone in acute and chronic pain. J Pain Symptom Manage. 2003;25(2):169-178.

14. Coda B, Tanaka A, Jacobson RC, Donaldson G, Chapman CR. Hydromorphone analgesia after intravenous bolus administration. Pain. 1997;71(1):41-48.

15. Greco C, Berde C. Pain management for the hospitalized pediatric patient. Pediatr Clin North Am. 2005;52(4):995-1027.

16. Hermens JM, Ebertz JM, Hanifin JM, Hirshman CA. Comparison of histamine release in human skin mast cells induced by morphine, fentanyl, and oxymorphone. Anesthesiology. 1985;62(2):124-129.
Journal of Pain Research

\section{Publish your work in this journal}

The Journal of Pain Research is an international, peer-reviewed, open access, online journal that welcomes laboratory and clinical findings in the fields of pain research and the prevention and management of pain. Original research, reviews, symposium reports, hypothesis formation and commentaries are all considered for publication.

\section{Dovepress}

The manuscript management system is completely online and includes a very quick and fair peer-review system, which is all easy to use. Visit http://www.dovepress.com/testimonials.php to read real quotes from published authors.

\footnotetext{
Submit your manuscript here: http://www.dovepress.com/journal-of-pain-research-journal
} 